\title{
The Experimental-Phonetic Analyses of the Discourse Intonation in the English and Azerbaijan Languages
}

\author{
Sahila Baghir Mustafayeva ${ }^{1}$ \\ ${ }^{1}$ Azerbaijan University of Languages, Azerbaijan \\ Correspondence: Sahila Baghir Mustafayeva, Azerbaijan University of Languages, Azerbaijan. E-mail: \\ sahilamustafa@yahoo.com
}

Received: May 2, 2020

Accepted: June 2, $2020 \quad$ Online Published: June 7, 2020

doi:10.5539/ijel.v10n4p184

URL: https://doi.org/10.5539/ijel.v10n4p184

\begin{abstract}
The article deals with the experimental-phonetic analyses of the discourse intonation in the English and Azerbaijan languages. Having researched the article, it becomes clear that discourse intonation (DI) is an approach to the teaching and analysis of everyday speech. The characteristics of intonation components in the formation of discourse have been touched upon in the article. The intonation is mentioned to be one of the main means in the formation of the discourse.

It is a known fact that speech styles can be characterized by their lexical, syntactic and phonetic features. The attention is drawn to the distinguishing points of the speech of the people having various professions such as the speech styles of a teacher and a driver should be different not only from the lexical point of view but also from the phonetic point of view.

During the conversation, one can come across some nuances of the speaker's intellectual level, life experience and social status. It is also important to remember that the subject of the conversation is meant to be an important factor too. The object of the conversation ensures the stylistic formation of the idea.

The importance of the experiment has been taken into a special consideration in the article as well. The opinion of academician L. V. Sherba that stresses the importance of the experiment has been analyzed by the author.

The factors that are needed to be followed by while carrying out the language facts have been fulfilled in the article.

The author tries to prove that DI is concerned with the speakers' moment-by-moment context-referenced choices. It recognizes four systems of speaker's choice: prominence, tone, melodicy, and termination.

The discourse samples having been chosen for the experiment are fulfilled by using various sentence types. Besides, the inside structure of the sentences and their lexical contents are also taken into account in the article.

Some discourse samples have been chosen in the comparable languages to be experimented in order to distinguish the intonation nature of the discourse. The experiment has been carried out by using the program "Praat". It is noteworthy to mention that the program "Praat" is known to be a computer operation used to analyze speech sounds.
\end{abstract}

Keywords: discourse, experiment, intonation, melodicy, intensivity, tone

\section{Introduction}

Intonation, the main means of communication, has been studied in recent linguistic research mainly in terms of the intonation organization of the speech continuum from both substantive and functional aspects. In recent years, researchers of intonation have preferred to study it in the structure of discourse, otherwise the picture of the intonation facts of isolated individual sentences may be distorted. Intonation can characterize relationships within discourse, that is, between different hierarchical units of discourse, such as syntagm and utterance. The function of intonation is not to syntactically actualize segments of discourse, but to realize the process of speech. In the process of communication, the transmission and reception of information is carried out through statements (syntagm) that represent the semantic, syntactic and phonetic whole. Lexical, grammatical and phonetic clauses are essential for adequate understanding of the information conveyed. Intonation is a phenomenon observed in a speech act, through which the semantic capacity of a sentence, predicative relations, communicative definitions, 
modality, as well as lexical structure and syntactic structure find their concrete expression. Intonation is the most accurate and economical super-segment event in the expression of the speaker's own pragmatic attitude in the act of speech. Intonation units, like other units of language, are subject to variation in the act of speech, both in terms of pronunciation and meaning, depending on the context and the point of speech.

Intonation is closely related to the expression of human emotions in a speech act. L. R. Zinder admits that intonation has such a function, "... but in the emotional field of intonation it is necessary to distinguish between its linguistic and non-linguistic aspects" (Zinder, 1979, p. 269). According to his opinion, "the features that characterize the speaker's attitude to what is said in the act of speech can be attributed to the linguistic aspect of emotional intonation, and the means of emotional intonation characterizing the general state of the speaker are not linguistic" (Zinder, 1979, p. 269).

It is important to mention that A. M. Peshkovsky is known to have touched about the relationship between syntax and intonation in linguistics. He writes: "We express what we say through narration, question and exclamation. No matter how important the difference between these three types of speech, the difference is not in the material aspect of the thought, but in its form of expression" (Peshkovskiy, 1957, p. 43). We would like to stress that A. M. Peshkovsky is known to be the author of the "principle of compensation". He claims that intonation is one of the grammatical means of the plan of expression, which is functionally similar to other grammatical units (Peshkovskiy, 1957, p. 181).

According to our mind that the more clearly a syntactic meaning is expressed by purely grammatical means, the weaker its intonation may be (to the point of disappearance), and conversely, the stronger the intonation, the weaker the grammatical expression (which is according to the degree of disappearance).

\section{Discussion}

One of the main features of modern linguistics is the study of the activity of the languages that is observed in the process of communication. Until the end of the twentieth century, in fact, the main focus in linguistics was on the study of the system and structural organization of the language. At present, linguists focus on the analysis of various factors that govern the communication process. The formation of an anthropocentric scientific paradigm in linguistics leads to the intensification of linguistic trends related to communication problems. F. Y. Veysalli notes that "when approaching communication in a semiotic plan, its consideration as an action carried out with the direct participation of linguo-semiotic means that is known to be one of the factors leading to the expansion of the discourse" (Veysalli, 2010, p. 9). According to N. I. Klushina, “... the dominance of the term discourse is a shining example of the change in the scientific paradigm in modern linguistics - the transition from the systematic study of linguistic phenomena (considering language as a system of systems) to the study of communication" (Klushina, 2011, p. 26). M. L. Makarov writes that "the definition of the category as a discourse requires a certain ideological tendency, a special approach to the study of language and verbal communication" (Makarov, 2003, pp. 84-85). Modern linguistics develops under the sign of discourse, according to M. L. Makarov, the role of the "category of discourse" among the social sciences can be equated with the role of the "euro in the European economy" (Makarov, 2003, p. 112).

The language-speech theory of F. de Saussure, the founder of structuralism, which is characterized by an immanent approach to language learning, is based on the claim of N. A. Chomsky's theory of language competence and language development (performance) (Chomsky, 1969, pp. 3-10). According to these theories, the central object of study in linguistics is the immutable, use-independent sign system or the grammar in the brains of language speakers. The language-speech theory of F. de Saussure, the founder of structuralism, which is characterized by an immanent approach to language learning, is based on the claim of $\mathrm{N}$. A. Chomsky's theory of language competence and language development (performance) (Chomsky, 1969, pp. 3-10).

The integration of the achievements of science in the direction of creating a general theory of communication is a peculiarity of the current stage of the humanities, at the heart of which is the problem of interaction at the level of language, personality, society and culture. Language plays a main role in solving the problem of interaction in the framework of integrative research, because it (language) acts as a mediator in all integrative processes. At the same time, the approach to language itself is changing radically, i.e., in recent years there has been an increase in the researcher's interest in the study of language in a discursive, more precisely, socio-cultural context. Different types of discourse are already of interest, which is related to the "anthropological turn" in linguistic research. The study of discourse is also the key to the study of a human, the society and the world.

According to the principle of anthropocentrism, a man is the point of reference in the analysis of language. The intensive study of language in various humanities and the use of discourse as the methodological basis of scientific analysis have made it possible to speak of a linguistic or discourse revolution. As a result, the object of 
research, the systems of descriptive coordinates changed: the text began to be studied in the relation to extra linguistic factors, the mechanism and processes of text formation became the object of research. A distinctive feature of the discourse paradigm, as stated by E. S. Kubryakova, was "the belief that it is impossible to learn neither grammar nor syntax without resorting to the use of language" (Kubryakova, 2000, p. 10). According to V. I. Karasik, who prioritizes the role of sociocultural context in the language comprehension, "discursive research is a field of interdisciplinary knowledge that is located at the intersection of linguistics, sociology, psychology, ethnography, and semiotics" (Karasik, 2002, p. 276). The linguistic description of the speaker's linguistic behavior in the communicative act is meant to be the issues of the verbal interaction in different speech situations, discourse genres, etc. are already on the agenda of linguistics which is observed to take place in the communication. According to E. V. Paducheva, the period of conversational acts, reference theory, in general, enriched with pragmatics, "for linguistics, to be content with only spoken language, that is, to approach language as a means of communication has already been closed (Paducheva, 1996, p. 219). In discourse analysis, a person acts as a subject of speech (speaker), consciousness, subject of linguistic identity, addressee and addressee (Paducheva, 1996, p. 156). Under these conditions, the concept of communication itself undergoes significant changes. Thus, the understanding of communication as a basic link between society, the transmission of information and the transmission of knowledge (transmission model) has its place in a broader understanding of this phenomenon - the symbolic formation of the identity of informants, their social connections and relationships, feelings and thoughts, social realities that is used in the understanding of the ability as a process of formation. This model emphasizes the importance of the role of communication in the formation of a human.

\subsection{The Novelty of the Research}

In modern linguistics, there is a growing interest in the study of language as a cognitive ability, which manifests itself in research aimed at identifying the two branches of human cognition-the activity of language tools involved in conceptualization and categorization. In linguistic research, there is a paradigm shift in the interaction of language and thought, the apparatus of categorical concepts of cognitive linguistics as an independent branch of linguistics is formed, the leading positions of human perception of information are identified. The essence of the cognitive approach is to approach the text as a unit of communication, the result of speech in the hierarchy of components of the discourse, combined with the pragmatic intention of the author within a certain communicative situation.

The study of the text-generating function of prosody is related to the relationship between semantics and intonation, which is one of the current issues in the field of intonation. Until recently, the study of the semantic functions of intonation was carried out by studying the intonation structure of isolated sentences, but today researchers studying intonation are trying to study the prosodic features of discourse composed of a set of sentences.

In the research work, the activity of intonation in the structure of discourse was studied from a pragmatic point of view. By the pragmatic function of intonation, we mean the movement of intonation tools in the process of integrating the meaning of a text. The main way to realize the pragmatic function of intonation is the prosodic organization of the text into units. Syntax is taken as a unit of text. In the research, the syntagm is mentioned to be used in the sense of academician L. V. Sherba.

Discourse theory is one of the most intensive areas of linguistics. However, many theoretical issues and discourse analysis have not been sufficiently studied. The content and structure of discourse is formed by from various conversational-act statements. However, the formation features of different types of discourse, their filling with illocutive types, the choice of appropriate syntactic constructions and their filling with appropriate lexical units were not the subject of separate research.

\subsection{Theoretical Significance of the Research}

The theoretical significance of the work is due to the study of the sound side of speech, i.e. the role of prosodic means in the expression of content (frequency, intensity, rhythm and quality of the main tone, etc.) in clarifying the semantic feature of the speech and its effect on precision intonation models. The theoretical significance of the work is not only to deepen its knowledge of the intonation system of English and Azerbaijani languages, but also to a) reveal the general and specific features of the intonation system of comparable languages, b) to develop a linguistic interpretation of multifaceted prosodic features of intercultural communication.

\subsection{Practical Significance of the Research}

The results of the analyzed language material obtained by the experimental-phonetic method can be used for practical purposes. Problem development can have a positive effect on the effective solution of foreign language 
teaching problems and automatic speech recognition. The results of the research can serve to improve the teaching process of English in the Azerbaijani audience and enrich the theoretical knowledge of the intonation features of discourse.

\section{Research Methods}

The following research methods have been used to carry out the present research work such as descriptive, acoustic analysis of the discourse samples, methods of mathematical and statistical calculation of results, etc. The application of the modern computer programs (Praat) in the study of sound signals has also been used in this research work.

Intonation can be considered to be one of the important tools in the formation of discourse. In order for the integration of lexical meanings that make up the general content of the discourse to take place, the boundaries of the components (syntagm, utterance) in the text structure must be defined. However, any act of speech is divided into groups with different structures for pronunciation due to its pronunciation duration (time). The member function of intonation includes defining the boundaries of syntactic units. Special attention is paid to the semantic role of membership only in cases of double interpretation, because syntagmatic membership eliminates dual interpretation.

The style of speech depends on the general psychological, intellectual and social level of the individual. We can also add the ability of individual discourse. The current political, economic and cultural environment also affects the style of speech. Depending on the speaking environment, the intellectual level of the applicant, etc. can be performed in the speech and in different forms.

Speech styles vary according to lexical, syntactic and phonetic features. Of course, the teacher and the driver must have different speech styles, and the speech styles differ not only lexically but also phonetically. In addition, there is a significant difference between a person's speech in the family and in a formal meeting. During the conversation, you can come across the nuances of the speaker's intellectual level, life experience and social status. It is also important to remember that the subject of the conversation is an important factor. Thus, the object of conversation provides the stylistic formation of the idea.

The study of any language material can be qualitative only if it is based more on experimentation. Academician L. V. Sherba emphasizes the superiority of the experiment. He writes: "I have known for a long time that it is impossible to reveal the meaning of the personal form of a verb through personal observation, for example, in Russian". It is noteworthy to mention that according to him, his linguistic ideas have always been based on the language materials and linguistic facts which were obtained from experiments.

The following steps were performed to perform the experiment correctly:

1) Announcers in both languages were selected to write down the experimental material, and then the experimental material was written;

2) The experimental material was written in both languages with the participation of two people, and in this way the announcers were compared;

3) When choosing announcers, special attention was paid to the observance of literary language norms in their speech;

4) The experimental material was read clearly and fluently;

5) During the presentation of the experimental material, care was taken to ensure that the announcers were not tired. This is because the sound that is read aloud at the beginning of the material begins to weaken as it ends. This can lead to erroneous results from the experiment.

6) Special attention was paid to the selection of material for the experiment. For example, in the Azerbaijani language, the same vowel is taken in the same phonetic scope. During the analysis, their quality characteristics were taken into account when calculating the sounds.

7) In the formation of discourse, special attention was paid to its intonation. The discourse pieces were chosen so that the sentence could have different meanings depending on the syntax. Instead of emphasizing syntax, which plays a crucial role in membership, attention was also paid to.

8) Different sentence types are reflected in the discourse examples we used in the research. At the same time, the internal structure and lexical structure of the sentences were taken into account. The experiment was performed using the Praat program. The program was created and developed by P. Boersma and D. Weenink from the University of Amsterdam. The program is very popular among linguists, especially among researchers studying 
the phonetic structure of the language.

\section{The Experiments of the Chosen Discourse Samples}

Now the intonation components in the formation of discourse in both languages are carried out like the following:

\section{In English}

Example I.

¿Do you know / how to hue the rainbow /?

Example II

¿Are you sure / he is in jeopardy /? As it is seen, the sentences have been divided into two syntagms (The syntagms are introduced by slash /).

The two sentences are used to introduce question discourses according to the type of intonation These two sentences have been pronounced in two syntagms by the two speakers.

The sentence ¿Are you sure he is in jeopardy? was pronounced in two syntagms by the first speaker though the second speaker pronounced the following sentence in one syntagm:

In the discourse ¿Do you know / how to hue the rainbow? the main tone frequency is observed to be in the range of $125-103 \mathrm{hs}$. The melodicy of the sentence is observed to be $108 \mathrm{hs}$ at the end of the progrediyent syntagm. It is $103 \mathrm{hs}$ in the terminal syntagm.

The main tone frequency is noticed to relevantly be $160-102 \mathrm{hs}$ as well as $76-100 \mathrm{hs}$ in the syntagms in the speech of the second announcer. At the end of terminal syntagms, a relative increase in melodicity is observed. The interval differences between the syntagms are the following:

a) it is $116-91 \mathrm{hs}$ in the speech of the first speaker;

b) it is $135-82 \mathrm{hs}$ in the speech of the second speaker.

The interval difference is $25 \mathrm{hs}$ in the speech of the first speaker; it is $53 \mathrm{hs}$ in the pronounciation of the second speaker (see Figure 1 I announcer, Figure 2 II announcer).

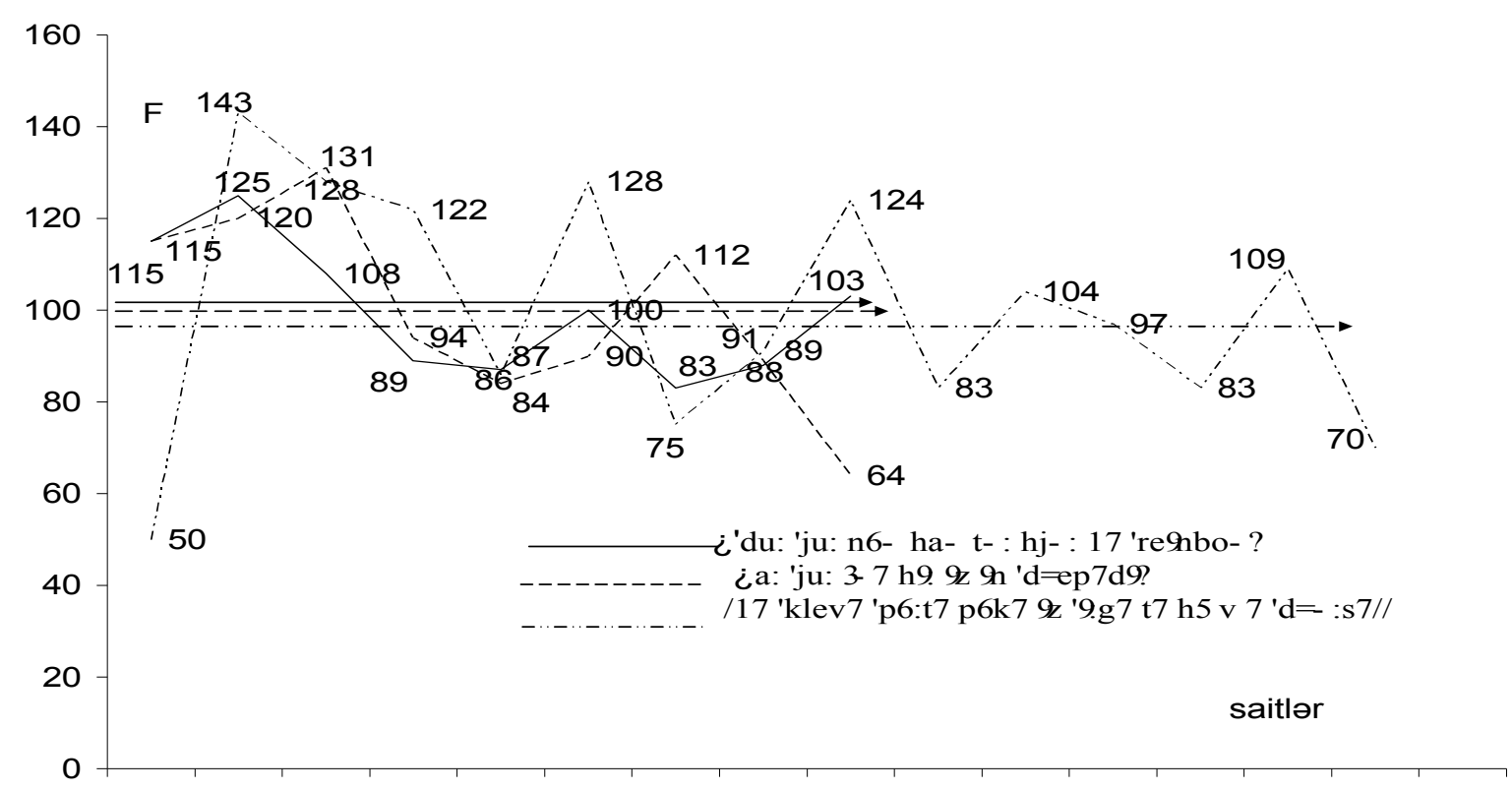

Figure 1. The melodicy of the discourses 


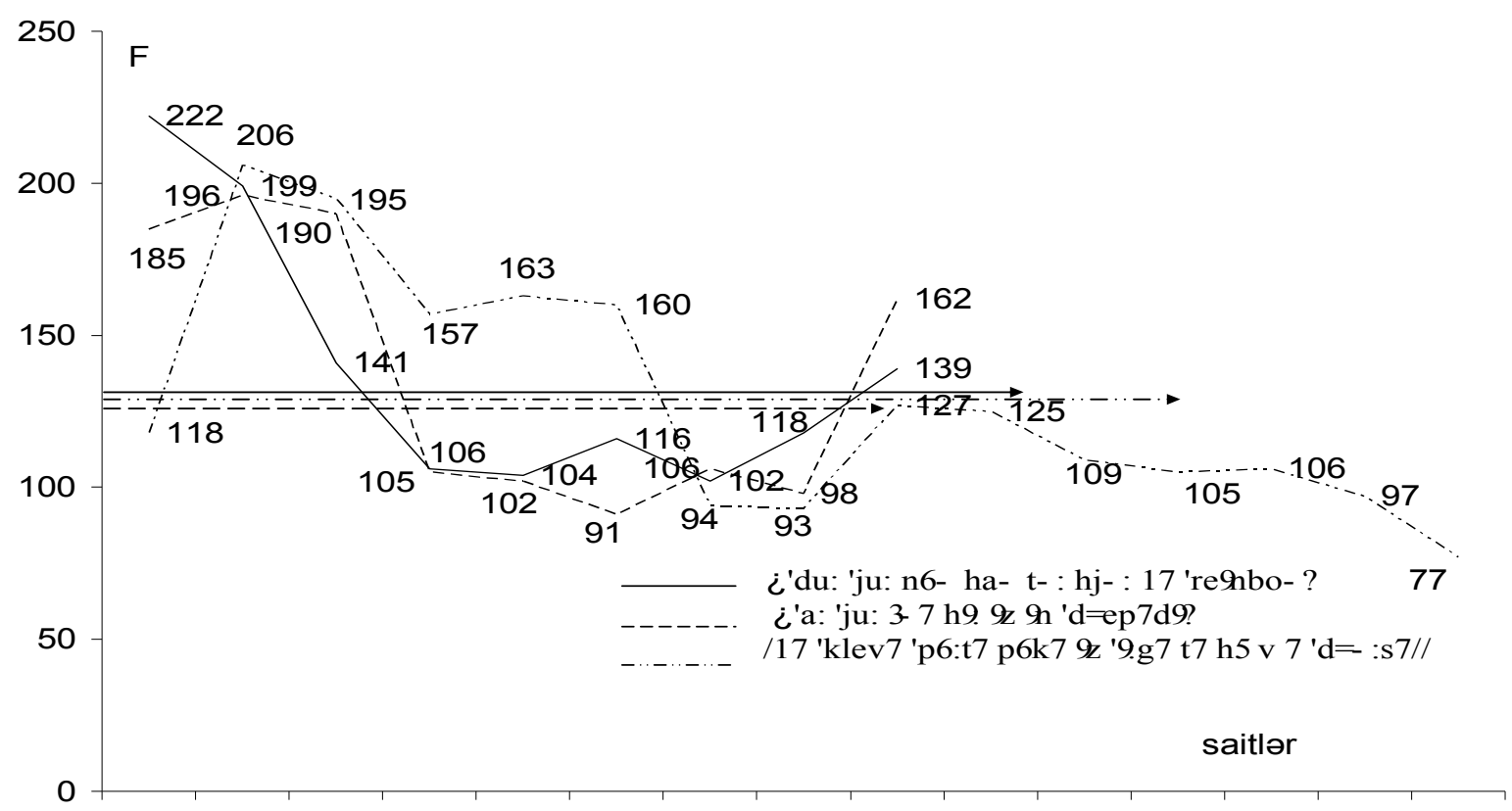

Figure 2. The intensity of the discourses

The next example in English.

In the sentence /The clever potter Poker is eager to have a juicer// /Ağıllı dulusçu Poker şirəçəkən almağa can atır// the declarative discourse is observed. The discourse has been pronounced in three syntagms by the two announcers. The tone frequency of the sentence /The clever potter/ Poker/ is eager to have a juicer// is observed to be $50-86 \mathrm{hs}, 128-75 \mathrm{hs}$ at the beginning syntagm by the first speaker; it is $91-126 \mathrm{hs}$ by the second speaker. It is $91-70 \mathrm{hs}$ in the terminal syntagm. The second speaker is observed to pronounce the sentence 91-126 hs, 124-72 hs, 72-59 hs (see Figures 1 and 2). The interval difference between the syntagms is observed to be 36-53-19 hs by the first speaker though it is 35-52-13 hs in the speech of the second speaker.

The example in the Azerbaijan language:

/Səlimi yenə də ağlamaq tutdu// /O, kövrələndə heç yerdə göz yaşlarını saxlaya bilmirdi// /İndi də atasının ayaqlarını qucaqlayıb ağlayırdı// (Salim began to cry again. Whenever he was sad, he couldn't control not to cry. Then he hugged his father's legs and cried). In this discourse the time parameters belonging to the declarative sentences have been noted. The time parameter is observed to be increasing at the end of each of the sentences. The time parameter is observed to be 114-94 m/sec., in the first syntagm, though it is 103-99 $\mathrm{m} / \mathrm{sec}$., in the second syntagm; it is $97-100 \mathrm{~m} / \mathrm{sec}$., in the third syntagm. At the end of all three syntagms, the time parameters are getting increased (see Figure 3). 


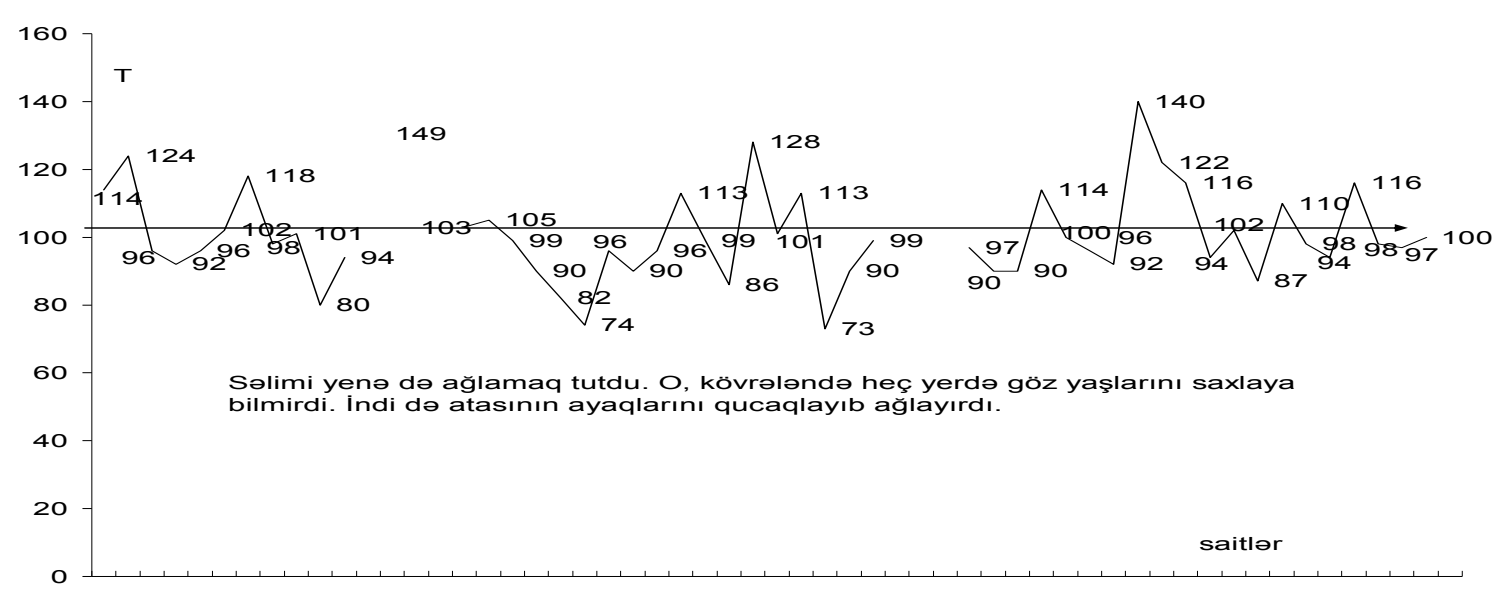

Figure 3. The melodicy of the discourses

The next example in Azerbaijan:

/Karvanbaşı başının düz üstündə dən-dən/, /duz-duz olmuş//bu şıltaq və yorğun ulduzları//yenə də heyran-heyran seyr eləməyində idi// This discourse was pronounced in four syntagms by the announcers. The tone frequency is observed to be $98-83 \mathrm{hs}$ at the beginning syntagm. The minimum tone frequency was noted at the end syntagm, and it is 74 hs (see Figure 4).

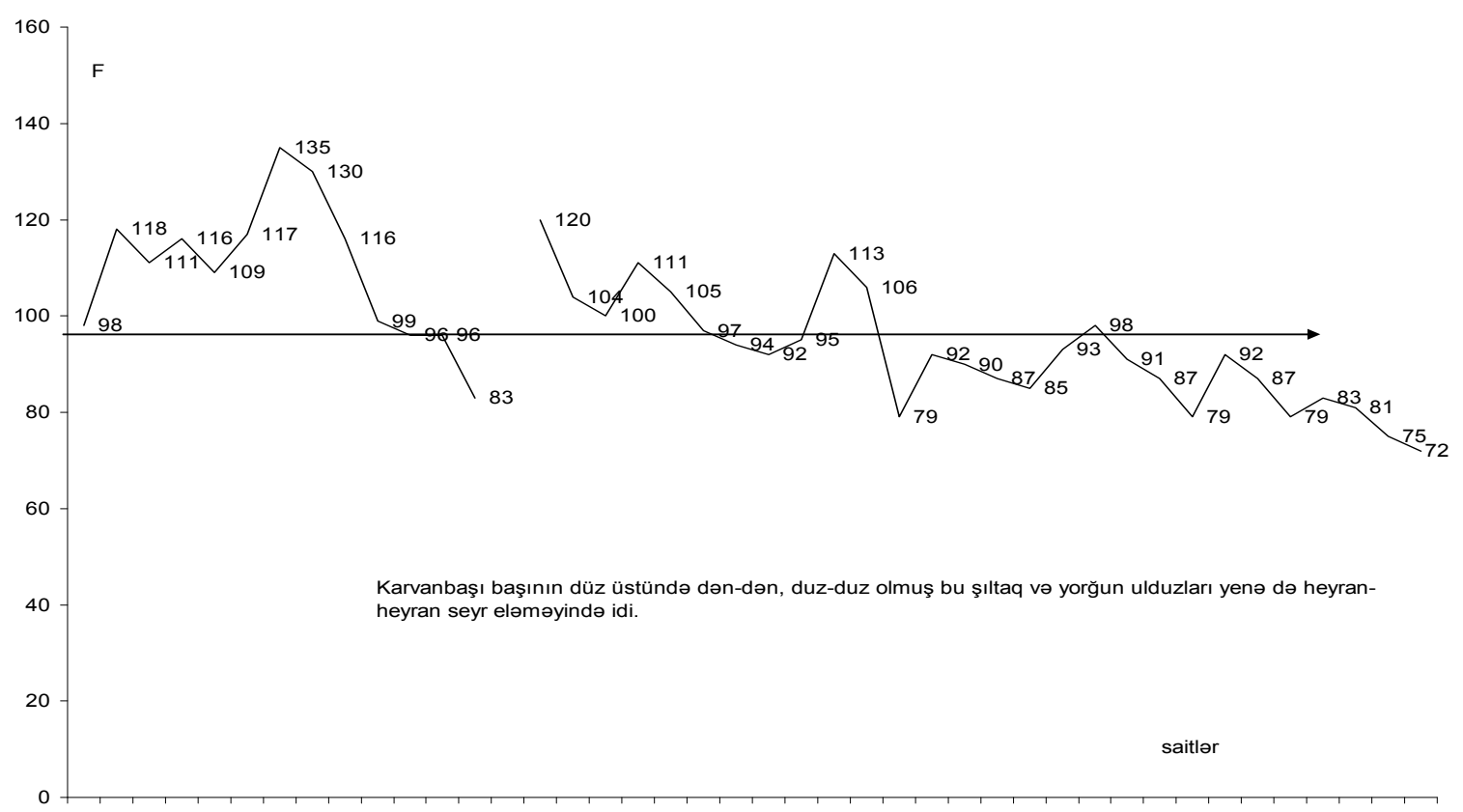

Figure 4. The tone frequency of the discourses

The experimental discourse samples in two languages give us the opportunity to come to the following results according to their intonation parameters:

\section{The melodicy}

a) the melodic organization of discourse in English and Azerbaijani depends on the point of conversation and the goals and objectives of communication. The intonation structure of a syntagm consists of a combination of the tonal levels of its individual parts. The central part has a special significance in the expression of the meaning of 
the syntagm. In addition, the intonation contour acts as a frame in the organization of the discourse. Lexical repetitions, syntactic and accent-melodic parallels in the discourse form its intonation shell. An important parameter of discourse is the similarity of accent-melodic structures of intonation groups, the alternation of stressed and unstressed syllables and, most importantly, the accent-melodic structure expressed by the localization of tone in the intonation core of the discourse.

\section{The intensity}

b) analysis of the intensity of discourse in both languages shows that this component depends mainly on the melodic component. The intensity is much higher in the syntax that precedes the last syntax of the discourse. Only in its last syntagm does the intensity decrease as the tone decreases. Thus, when a person begins to speak, he has a lot of strength and energy. However, as the articulation program ends, the person's energy is depleted, resulting in a decrease in intensity.

\section{The tone}

c) analysis of the time parameter of the discourse in both languages shows that in its final syntax, as a rule, the time parameter weakens. This is because the tone of voice falls near the end of the discourse and the tone weakens.

\section{Conclusion}

A review of the scientific and theoretical literature on the study of discourse intonation shows the importance of a cognitive-discursive position in the analysis of discourse, along with anthropocentric parameters (intensity, emotional state, social status, cultural background, attitude to cognitive and communicative structures, etc.).

An intonation analysis of discourse shows that a number of scholars claim that the members of the discourse are divided into paragraphs according to the written form. Given that the discourse is primarily about the point of conversation, it is impossible to agree with the way the issue is put. We think that the intonation plays an important role in the organization of discourse, and syntagm should be taken as a unit of this membership.

The intonation components listed above divide discourse into syntagms in comparable languages, ensuring its formal and semantic comprehension.

The prosodic organization of discourse in both languages arises from the complex interaction of all components of intonation. For the prosodic components to reach an effective end, it is important to increase or decrease the tempo between the individual components, to increase or decrease the intensity, to have a sharp rise and fall of the tone within the melodic contours, and to have breaks.

\section{References}

Abdulla, K. (2006). Valley of Wizards (p. 224). Baku: Mutarjim.

Chomsky, A. N. (1969). Aspects of the Theory of Syntax (p. 261). England: MIT Press.

Karasik, V. I. (2002). Language circle: personality, concepts, discourse (p. 477). Volgograd: Peremena.

Klushina, N. I. (2011). From style to discourse: a new page in linguistics // Language, communication and social environment. Voronej, 25-33.

Kubryakova, E. S. (2000). On the concepts of discourse and discursive analysis in modern linguistics/Discourse, speech, speech activity: functional and structural aspects (pp. 7-25). Moscow: Progress.

Makarov, V. V. (2003). Fundamentals of Discourse Theory (p. 280). Moscow: Gnozis.

Mammadov, A. Y., \& Mammadov, M. (2010). The cognitive perspectives of discourse analysis (p. 96). Baku: Chashioghlu.

Paducheva, E. V. (1996). Semantic research: semantics of time and type in Russian. The semantics of the narrative (p. 464). Moscow: Languages of Russian Culture.

Peshkovskiy, A. M. (1957). Russian syntax in the scientific field (p. 511). Moscow: Progress.

Veysalli, F. Y. (2010). Introduction to the discourse analyses (p. 141). Baku: Education NPM.

William, S. H. (1599). Julius Caesar (play). London: G. Eld for T. T.

Zinder, L. P. (1979). General Phonetics (p. 312). Moscow: Higher school. 


\section{Copyrights}

Copyright for this article is retained by the author, with first publication rights granted to the journal.

This is an open-access article distributed under the terms and conditions of the Creative Commons Attribution license (http://creativecommons.org/licenses/by/4.0/). 